Cite as: Righi V, Sayago S, Rosales A, Ferreira SM, Blat J. Co-designing with a community of older learners for over 10 years by moving user-driven participation from the margin to the centre. CoDesign. 2018;14(1):32-44. DOI: 10.1080/15710882.2018.1424206

\title{
Co-designing with a community of older learners for over 10 years by moving user- driven participation from the margin to the centre.
}

\begin{abstract}
This paper addresses a gap in the Participatory Design (PD) literature, wherein more research on the long-term impact of design projects is warranted. This paper reflects on a 10 -year study that intertwined ethnography and 2 PD projects in a community of older learners. Although the goal of our study was to design new digital technologies, the process of designing them presented us with opportunities that gave rise to new non-digital practices, which turned out to be the legacy and most significant outcomes of the PD projects. This result invited us to review the trajectory that led to these outcomes. Our analysis shows that the most important legacy aspect of the projects arose from unexpected forms of user-driven participation that we allowed to co-exist together with those practices more related to the design goals of the PD projects. Drawing upon our results, this paper posits that engagement with PD participants that unfolds over an extended period of time is instrumental in facilitating the development of participation, understanding more deeply long-lasting project outcomes, and legitimizing forms of participation that are not directly related to project/design goals.
\end{abstract}

Keywords: legacy, long-term, community-based participatory design, ageing

\section{Introduction}

Design is often seen as an activity that happens in discrete phases. Within Research and Development $(\mathrm{R} \& D)$ projects, classical phases are analysis, design conceptualization and implementation / development. However, this view of design is rather constrained. There is growing awareness that design continues when people use and appropriate technologies in their lives (Silverstone and Haddon, 1996; Pipek and Wulf, 2009; Storni, 2010). Yet, participatory design (PD) activities are seldom seen from this long-term perspective. A review of 10 years of PD 
publications (Halskov and Hansen, 2015) shows that most PD studies focused on discrete design activities, failing to analyse the way in which two or more design phases have an effect on each other over time. Whilst this might be accounted for the fact that "most PD projects are not in a position to follow up on the changes that may happen after project time" (Bratteteig and Wagner, 2016, p. 148), a growing number of works contend that without adopting a long-term perspective, it might be difficult to argue whether the key values embedded in PD studies (e.g., mutual-learning, empowerment, democratization and changes in practices) have been met (Balka, 2010; Bossen et al., 2016; Bratteteig and Wagner, 2016), or to discuss the fate of the prototypes developed during the project (Taylor, 2013).

This paper reflects on the key results of a long-term engagement in PD with a community of older people. It draws upon 2 PD studies conducted within the context of two R\&D projects aimed to co-design new technologies for enhancing older people's social interactions ( Life 2.0,20102013), and new digital games that are meaningful, playable and appealing for them (WorthPlay, 2012-2013). This paper also draws upon 3 ethnographic studies of digital technologies use by older people conducted over a decade. This paper reconstructs the trajectory that led to the constitution of long-lasting practices among the group of older people who participated in the PD projects. These practices - a mutual help group on smartphone use and city routes of a reading club - are still ongoing at the time of writing this paper. We consider them noteworthy examples of the legacy of our PD activities in the projects, even though these activities do not rely on the technologies that were co-designed in them. With the term legacy we refer to what is left behind when PD researchers leave the field and how what they seeded during the project continues afterwards.

Management and technical issues in the projects caused idle times during which it was difficult for us to define the goal and have participants engage in the design activities. Yet, we deemed it was important to keep our participants involved in the projects and asked them to suggest ideas during 'unproductive' periods. They suggested, amongst other activities, setting up a 'smartphone' group, so that they could learn how to use these technologies. We considered that 
these activities were related to the projects. Yet, they were not intended to address fully their design goals. Even so, we carried out these activities because we deemed them instrumental for understanding the design setting. Over the course of the projects and ethnographic research, we realised and understood, thanks to our deep immersion in the community, that these 'unplanned' activities played a key role in determining the legacy of our PD projects. These activities were also instrumental in sustaining our participants' long-term engagement in, and contributions to, the projects, because they fitted in within the community's goals, interests and dynamics. This type of unexpected, user-driven participatory configurations is seldom discussed in PD research, as it tends to concentrate on scaffolding participation around projects proposals' design goals.

\section{Older People in PD: strong focus on adaptation, the temporal perspective is overlooked}

While there is growing awareness in the field of technologies design that engaging older people in design activities is of the utmost importance to create better digital technologies (Newell, 2011), involving them effectively in co-design is a challenge. Older people find it difficult to conduct creative thinking tasks (Otjaques et. al. 2010) and so feel uncomfortable when they are asked to draw, sketch or comment on interface design issues (Mitchell and Nørgaard 2011, Rice and Carmichel, 2011, Uzor et. al., 2012.). They also tend to show a lack of technical experience (Joshi \& Bratteteig, 2016), and a weak identification with the predefined goals of the project (Joshi \& Bratteteig, 2016). In an attempt to overcome these issues, researchers have focused on tailoring codesign techniques and activities to older people (e.g. Lindsay et al., 2012; Rogers et al., 2014; Vines et al., 2012; Leong and Robertson, 2016).

In keeping with PD studies conducted with other user groups, most PD studies with older people are carried out at early stages of the design process, and their involvement in them tends to be limited to one or few staged sessions (e.g. Chen and Wang, 2012; Cozza et al., 2016; Robertson et al., 2014; Rogers et al., 2014) 
The results of most PD studies with older people fall into two categories: a) design considerations for future technologies, b) the design and development of artefacts. Yet, other important results of PD studies, such as what participants gain from the participatory process (Bossen et al., 2010), are mostly overlooked. Some benefits reported by older people included the satisfaction of contributing to combating aging myths (Joshi and Bratteteig, 2016). We agree with (Bossen et al., 2016) that researchers should engage more deeply in assessing the outcomes of PD processes, and do this beyond the temporal frame of the project.

However, long-term PD studies conducted with older people are rare. A noteworthy example is (Botero and Hysalo 2013), which reports on a community-based PD studies aimed to sustain their participation over an extended period of time. Community-based PD has proven to be an effective way to achieve this goal, since it can contribute to foster participants' ownership of the process and the developed technology, and to respond to participants' evolving needs.

This paper draws upon and extends (Bossen et al., 2010; Botero and Hysalo 2013) by focusing on i) forms of legacy left by PD projects, and ii) types of participatory configurations that contribute to it. It does so by combining community-based PD and ethnography.

\section{Ten years of research and design}

The research summarised in this paper was conducted by 4 Human-Computer Interaction researchers between 2005 and 2015. During this period of time, we conducted 3 ethnographic studies of digital technologies use by older people, and 2 PD studies in R\&D projects (Life 2.0 and WorthPlay) intended to co-design novel interactive technologies for them. The ethnographic studies were conducted before, during and after the projects, aiming to better understand the relationship between older people and digital technologies.

We conducted our research in Àgora (AG), an adult educational centre in Barcelona (Spain), which offers a broad array of free courses (e.g., foreign languages, literacy, computers and the 
Internet). Approximately 450 active older people (55-80 years old) were involved in the study, of which 120 participated in Life 2.0 and 310 in Worthplay.

\section{Three ethnographic studies}

The ethnographic studies (Study A: 2005-2008, Studies B \& C: 2010-2015) explored older people's everyday life and their relation with digital technologies from different perspectives. Study A focused on understanding their use of Computer Mediated Communication tools. Study B focused on online content creation and sharing technologies, such as YouTube and video editing tools. Study C widened the focus on the design of digital technologies, applying an ethnographical lens on the design processes conducted during the two R\&D projects.

The ethnographic studies were mainly conducted during the educational activities offered in AG. We observed and talked with older people while they were using computers, the Internet and a wide range of software tools. We also participated in other activities (e.g., events, cultural gatherings, language classes) so as to gain a deeper understanding of the community, the local neighbourhood, and facets of our participants' lives. Furthermore, we created two groups (approximately 50 participants in both of them), one in Facebook and the other in Whatsapp, to keep in touch with them during and after our research.

\section{Two community-based PD studies}

The projects were structured into three iterative phases: analysis, conceptualization and evaluation.

Life 2.0 aimed to generate new opportunities for social interaction by building services that enable older people to connect with people living in their local area. With its focus on social interactions, the project aimed to shed light on the many aspects of older people's lives, besides health issues, which tend to be the goal of many technologies and services aimed at them. The analysis phase focused on understanding older people's everyday lives and their use of digital technologies through rapid ethnography (Millen, 2000). In order to translate ethnographical insights 
into a design concept, we conduced 2 PD workshops wherein participants were invited to envision future scenarios by means of storytelling and personas. As a result of the PD activities, we decided to develop a social networking platform to enable older people to offer their knowledge and skills to their neighbours, and to help them keep abreast of social events, commercial services and assistance available in their local area. The evaluation phase lasted approximately 20 months and ran in parallel to the development of the platform. We adopted a design-in-use approach (Dittrich, 2002) to reinterpret and adapt the initial design concept. To encourage the uptake of the platform and to support the design-in-use approach, we established a core group of 18 participants. We met them weekly in the AG computers room. The meetings were structured as regular computing courses in which participants learned to use a variety of technologies and interacted with prototypes of the platform.

WorthPlay aimed to understand and develop meaningful and appealing digital games for older people. The project was driven by the desire to bring some clarity on the contradictions, inconsistencies and gaps present in the literature on older people and digital games (Sayago et al., 2016). The analysis phase was aimed at understanding their gameplay. We did so by drawing upon rapid ethnography (Millen, 2000). We observed older people playing a variety of digital and tabletop games, by either setting up playing clubs or proposing games in courses. In order to translate ethnographical insights into a game concept, we carried out 9 co-design sessions, wherein participants created and played games that they found worthwhile to play (Sayago et al., 2016). Games were simulated by using papers, posts-its and MS PowerPoint. As a result of the whole design process, we developed an online gaming platform, which allows older people (and members of their social circles) to both create and play different types of online quiz games. We evaluated the platform over a 3-month period in playful sessions wherein participants were invited to create and play games by using the developed platform. 


\section{Data gathering and analysis}

Over a 10-year period, we took paper notes of our first-hand observations, informal and more formal (e.g., semi-structured interviews) conversations with the participants. The interviews were intended to know more about their everyday practices and opinions on the technologies developed in the PD projects. We also took pictures of them interacting with digital technologies and gathered online conversations in the Facebook and WhatsApp groups.

These data were analysed recursively by 4 researchers throughout the duration of the study by using thematic analysis (Braun and Clarke, 2006). For the scope of this paper, we selected those themes that emerged from our previous analyses and that are related to the current one. We organize the results in chronological order to reconstruct the key aspects that contributed to the PD legacy.

\section{Results}

This section presents the most relevant outcomes and impact of the PD projects by reconstructing the trajectory that led to them. We focus on the key moments of participation and we discuss how they are related to the original goals of the projects.

\section{Setting the stage by building the vision}

When writing project proposals, common tasks are to (i) identify the problems to be addressed, (ii) articulate and frame those problems in a certain way, and (iii) conceptualize potential users according to the identified problems. Thus, projects implicitly start before they are officially due to begin. We argue that this initial framing has a lot of influence on the way participation is configured and enacted over the course of a project. Our first ethnographic study determined our research agenda and the way we conceptualized both older people and their participation in design projects. 
Setting the vision of the projects

Our long-term engagement in AG started in 2005, when the ethnographic study (A) started. Contrary to widespread and fairly negative stereotyped views of older people and computers (e.g., older people are unable to use them), the results of this 3-year study portrayed older people as social actors (Sayago, 2009). Over time, and with a lot of determination and motivation, older people are, or aspire to become, active, ordinary (i.e., using mainstream technologies rather than others designed especially for them), social and independent (i.e., using technologies on their own) users. This initial research helped us understand that we should avoid stereotyped views of older adults and understand their motivations, aspirations and interests, as well as the communities to which they belong.

By embracing the vision of 'older people as social actors', we became committed to promoting their active participation in our research activities. We aimed to provide them with opportunities to shape, plan and drive our research agenda. Following up on Study A, our research was designed to be meaningful for our participants and fit in AG activities. These two aspects were key so that AG trusted us. Trust manifested itself in the way AG granted us permission to conduct our research over a decade. We were invited (by members of the AG staff) to participate in the community by sharing our opinions and ideas in plenary meetings where a number of different issues, ranging from problems to ideas, were discussed. We were also allowed to conduct research and design activities without obtaining the official or formal 'go ahead' of the board. We felt at (our second) home.

Studies B and C were run in parallel and after the two PD projects. In addition to taking part in the project activities, we ran computing classes and participated in social community events. Socializing with the participants in informal meetings, which did not occur within staged design activities, enabled us to establish a friendly and trustworthy relationship with them. This participation in the community facilitated communication and dynamics during more formal design activities, as participants felt comfortable sharing with us their feelings and opinions about the 
projects. As a result of these conversations, we were able to understand the way in which our participants understood the project/s and the technologies in a natural fashion - i.e., without asking them about these issues more formally, e.g., interviews.

\section{Being on the stage by looking behind the scenes}

Over the course of the study, we realized that the real challenge of participation was to make older people feel the owners of the project (i.e., make decisions regarding which direction the project should take and be willing to appropriate their outcomes). Despite contributing actively to the design process, our overall impression was that they did so because we asked them to help us. For instance, at the end of the co-design sessions, they usually asked us: 'did we help you today? Did you get what you need for your project?' In other words, they were (enjoying) helping us, but they did not feel they were building something for themselves. We considered that without a real interest in our research, our results would be of little value to them. This represented a turning point in the way we conceptualized our research agenda. Our long-term engagement in AG -at that time, we had been conducted research with AG participants for 4 years - prompted us to strongly commit ourselves to paying respect to the will and desires of the community. Thus, instead of expecting the community to be unconditionally interested in our design goals, we became open to the idea of adapting the agenda of the PD projects to the community expectations and interests. How could we foster community ownership of the project, thus allowing possible new outcomes to emerge, while complying with what we promised to deliver in the project proposal?

We addressed this issue in two ways. In order to keep with our goal of building new technologies, we shaped the initial design concepts to meet the community goals. For instance, the Mutual help service in Life 2.0 was transformed in a knowledge sharing service, and the game platform in WorthPlay was designed to enable the creation of educational quiz games. Both design concepts aimed to make the most of participants' interests in learning. To allow the emergence of new research directions that addressed more directly the community's will, we promoted activities 
and embraced other forms of technology appropriation than those directly related to the project goals. These activities were conducted in the use phase, when a first prototype of the platforms was developed and introduced to the participants. We focus on the latter aspect because it was crucial to the legacy of the projects.

\section{The value of idle times and taking into account the community}

A 20 -month evaluation phase in Life 2.0 was conducted in parallel to the development phase and was aimed to i) understand participants' use of the platform, in order to fine-tune its functionalities and inform its continuous development, and ii) assess the impact of the technology on their everyday life. To this end, we set up a core group of 18 participants and organized weekly meetings in AG in order to both test the platform and observe how they used it. During these meetings, there were times in which the platform could not be used, because of technical issues, which prevented us from achieving the evaluation goals. In parallel to that, we soon realized that we could not expect to ask the participants to use the platform and assume that they would automatically incorporate it in their daily practices. We needed to find a way to foster its appropriation. We took advantage of the idle times to run other types of activities that were not directly related to the project goals. For instance, we turned the weekly encounters into informal computing classes wherein participants learned to use technologies they were interested in, such as Facebook. To this end, we set up a Facebook group, which became another opportunity to socialize. The weekly meetings became the excuse for using other technologies than those developed in the project. These meetings also helped the participants (and us) to know each other better and make the interests and needs of the group more evident (e.g., learning technologies, ask help related to technologies use).

The value that the participants saw in participating in the project was not related to the technology they contributed to design, but in the possibility of socializing and building a sense of community of which they felt the owners. This is clear, for instance, if we consider the way in 
which they talked about their participation in the project to other people: 'We are the ICT group on Facebook. We meet every week we learn to use technologies'. Paradoxically, they did not identify themselves with the technology they co-designed, but with the one we used to sustain their engagement.

At the time of running the project, this form of engagement was not regarded as being strongly related to its goals - because, for instance, it did not contribute to foster the adoption of our platform. Yet, the strong sense of community raised by this type of participation fostered a sense of ownership of the project by the group of participants, who started to show a strong interest in making it a success. During the course of the project, they organized activities in two elderly centres in their neighbourhood with the aim of inviting them to join the group. We did not ask them to conduct these activities. Some months after the end of the project, we realized that this type of participation was instrumental in enabling what the legacy of Life 2.0 was.

\section{Exploring unexpected forms of appropriation}

The evaluation phase in WorthPlay lasted 3 months, period during which we conducted playful activities in 4 different AG courses. One of them was a book-reading club. The activity was designed around the idea of following a route (similar to touristic ones). In this route, a series of geo-localized questions pop up on the screen of tablets and / or smartphones. The questions were about the book the participants were reading. Some members of the book club created the questions. The activity consisted of using the WorthPlay platform to answer the questions in situ and earning points by 'competing' with other groups.

Our observations suggested that the key driver of the activity was not the game per se but the discussions and comments stimulated by the questions. These discussions did not differ significantly from the ones that took place in the book-reading club at AG, i.e., participants brought the book in the activity and read parts of it when there was disagreement on some questions. Thus, rather than people adapting to the technology (for instance, by simply playing the game and 
competing), they conceived of the technology as a trigger of new ways of carrying out ordinary and meaningful activities.

This changed dramatically our research plan in the project and the resulting technology. The project set out to design a couple of games for older people. However, and in light of these results, we ended up co-designing an online platform whereby they could create their own games. It might be questioned to what extent the way in which the group used the platform could be considered a game. For instance, it is worthwhile to reflect on the fact that the participants never referred to the activity by using the term game, instead they called it 'literary route'. This different way of appropriating, conceptualizing and talking about the designed technology is relevant if we consider that it paved the way to what resulted to be the legacy of WorthPlay.

\section{Leaving the stage by interrogating ideas of legacy}

After a long-term engagement in PD with a community, it is worth asking what was left behind after the end of the projects. Two prototypes were developed. However, the Life 2.0 platform was shut down a few months after the end of the project. The WorthPlay platform is online, though technical support is no longer offered.

The technology our participants contributed to design could be considered a form of legacy. However, did participants really use it after the end of the project/s? If not, how does this inform the results? What other forms of legacy are possible? It is difficult, if not impossible, to answer these questions if research stops when the project ends. To this end, we decided to keep our engagement in AG after the completion of the projects. We did so by reducing our participation in the community, from one time per week to once per month and then every three months approximately. We keep in touch with some participants through the WhatsApp group whereby they often post information about their planned activities. This allowed us to address the aforementioned questions.

The legacy of both PD projects was the formation of new practices among groups of participants. These practices arose from those activities that, at the time of running the project, were 
considered either distractive -the weekly meetings in Life 2.0 - or disruptive -the book-reading club using the online platform in new ways in WorthPlay.

\section{Inspiring new digital-related practices}

At the time of writing this paper, the core group of Life 2.0 participants is still meeting on a weekly basis. The participants set up a mutual help group where they teach each other tips and tricks about smartphones. Each week a member of the group prepares a topic (e.g., how to use an app), announces it on the WhatsApp group, and shares with the other members what s/he knows about it in a face-to-face meeting in AG.

We do not attend these meetings anymore, though we still keep in touch with them through the WhatsApp group and we are always invited to the lunch celebrations they organize every 3 months. The many discussions we had about sharing help during the Life 2.0 meetings have perhaps inspired the formation of these sharing practices. We feel confident enough to claim that socialization has been one of the biggest results of the project, and that socialization certainly gave rise to these new practices. In fact, when we conducted a structured interview to understand the perceived outcomes of the project, the most often answer to the question 'did the Life 2.0 platform improve your quality of life?' was: 'Of course, we created a very good group of friends!' It is therefore clear that socialization was not fostered by the technology per se, which was barely used for testing purposes, but by the engagement that was embedded in the PD process.

The success of the Life 2.0 project did not depend on the extent to which the new tool supported older people's daily lives - the initial goal of our research. Indeed, the technology developed in the project was never adopted. Rather, it relied on the way in which we re-designed our agenda around the goal of (i) making explicit, and capitalizing on, the shared interests and practices of the participants, (ii) orchestrating participation around these shared interests/practices, and (iii) building upon existing technologies (WhatsApp, Facebook) to fulfil their interests. 
WorthPlay finished in 2013. However, the book-reading club, which was involved in the project, organizes literature routes every 6 months. The activity is now slightly different from the one we proposed, as it is no longer based on answering questions. Two members of the group prepare the route by selecting the path and gathering information about it (e.g., buildings, anecdotes and history). Although the technology we developed is not used in this new activity, others technologies are employed, such as Wikipedia, to gather information of the locations, and digital cameras, to record the activity in situ. We do not take part in the preparation of the activity anymore. We are invited by the group to take part in their routes occasionally. The original WorthPlay activity triggered a new practice, but the online platform is not central to it. We thus claim that the designed technology was appropriated, transformed and integrated, until its dissolution within the community practices (and other technologies).

\section{Discussion}

In this section we discuss the results of our study by relating them to current trends in PD.

\section{What is a PD result and who decides it?}

The main expected results of our PD studies were digital artefacts. However, the legacy of our studies turned out to be new everyday practices that are (and can be) conducted without the codesigned technologies. This key finding has invited us, who come from participatory-HCI, to reflect on the extent to which the technology-driven framing of our research can hinder other types of nondigital outcomes. In other words, how can PD support, and build the ground for, non-digital practices while keeping with its technological research agenda?

This question is aligned with, and contributes to, the current debate in the PD community on what a PD result is. There are two main discourses: i) the democratic, within which a PD result is the one that "shows evidence of democratic ideals' by increasing the agency of its users and giving them a voice in matters they did not have before" (Bratteteig and Wagner, 2016), and ii) the 
technological, on which the results of PD are essentially digital artefacts that support and empower aspects of users' work/lives (Korsgaard et al., 2016).

The long-term results of our PD study indicate that the main outcome is aligned with the democratic discourse. Regardless of the strong or weak effect the new practices had on the quality of life of the participants (e.g., to what extent does creating city routes improve older people's lives?), the way in which the participants exercised and exhibited their agency is worth noting. This does not mean, however, that the technological discourse is not addressed in the results. The discussions and participation were orchestrated around technologies. Yet, the technological result of our PD activities was not the same as the one envisioned in the initial idea of the projects. The technology was re-interpreted by the participants. Thus, there are reasons to argue that the PD result should not only be evaluated (by us) against the goals of a project, but also according to the endurance of the changes brought in the community (i.e., new practices), by taking into account participants' opinions.

In both Life 2.0 and WorthPlay, what we finally designed can be regarded as socio-material assemblies (Bjögvinsson et al., 2012), wherein a dialogue between people's everyday needs / practices / interests and the opportunities opened up by the introduced technology is established. This dialogue is unlikely to happen if participation is limited to the development of a particular technology. In fact, this vision 'downplays [...] the story of people who may be less interested in artifacts per se and their novelty, but more concerned about how to use all available resources, including interactive technologies -irrespective of whether or not they are 'novel'- to further develop their practices and improve their environments' (Kaptelinin and Bannon, 2012, p.287).

\section{Which participatory configuration facilitates a long-lasting PD result?}

The legacy of our projects resulted from forms of participation which were not aimed to address fully the design goals of the projects. In Life 2.0, by running community-building activities and promoting discussion about sharing help, we unintentionally motivated older people to set up a 
mutual help group after the end of the project. In WorthPlay, by promoting different ways of using the gaming platform within established contexts and practices, we triggered a new activity (literary tours) related to an already established one (reading books) and introduced digital technologies into it, though not the one we developed. All these activities generated new knowledge and opened up opportunities which were not considered at initial stages of the projects.

It is worth noting that these forms of enduring participation were not designed by the researchers in an attempt to engage participants in the project activities. Rather, they were proposed and carried out by the same participants. Yet, they did not 'just happen'. By embedding the projectbased PD activities within existing community practices, we set up a fertile ground to foster participants' agency, which enabled their appropriation of the research agenda and the shaping and re-shaping of the activities according to their interests and practices. Also, by immersing ourselves in the design context, participating in 'unproductive' activities and showing commitment towards the community, we realized the richness of the entire AG community (not only the group of selected participants). We also understood that there was a wide range of opportunities that could be realized if we were able to open our agenda.

We consider that this form of user-driven participation differs considerably from the one that predominates in the literature of PD wherein the main focus is on the "front stage design activities such as workshops or cooperative prototyping, where designers, researchers, participants, and stakeholders come together to work on the object of design" (Bødker et al., 2017, p.4). It also challenges widespread approaches in PD with older people, such as having them involved in design activities according to researchers' goals, and conducting PD with older people that do not know one another, instead of seeking people who share a concern or interest (DiSalvo et al., 2013). The interests of the researchers seem to prevail over those of the participants. 


\section{How does user-driven participation impact on the design of technologies?}

The pragmatic focus of our research agenda (i.e. build a 'thing') inevitably mitigated over the course of the study, but was never completely lost. In fact, the user-driven participatory approach encouraged us to re-define the goals of the online platforms. In the case of Life 2.0, the initial focus on mutual help was turned into fostering peer-to-peer knowledge sharing by means of 'ordinary' technologies. With respect to WorthPlay, the participatory practices helped us to understand that a single game was unlikely to cater for our participants' varied interests in games. We therefore decided to design a platform of games.

The participatory practices also allowed us to re-design the vision of older people in PD. We started by thinking of them as social actors. Throughout the project, and afterwards, this vision turned into seeing them as co-designers and owners of the participatory process. This had a considerable influence in the conceptual design of technologies as well. The technology should (i) enable older people to decide what they want (e.g. creating your own game, rather than the one created by other stakeholders), (ii) be designed by taking into account the artefacts that they currently use to support their practices, and (iii) consider whether a new technology is needed to meet design goals or whether this objective can be achieved by fostering creative/different uses of those technologies they already use.

\section{Why a long-term perspective is needed?}

In hindsight, the long-term aspect of our research and legacy of our PD study have enabled and encouraged us to realize that it is important to look beyond our design-oriented goals and the timeframe of PD projects in order to understand the true impact of PD activities. This lesson we have learned and shared in this paper would have been impossible without observing how what we seeded during the project time grew afterwards. We have been fortunate enough to conduct 10 years of ethnography and be able to witness and understand whether and how our 'designs' (both artefacts and practices) affected our participants in their everyday lives. Similar studies might be difficult to conduct, but we encourage researchers and designers to take into account how their practices and 
interactions unfold over extended periods of time, and ultimately contribute to make a lasting impact on local communities.

\section{Conclusion}

By drawing upon ten years of research and design in a community of older learners, we have presented a longitudinal perspective on PD. This perspective has allowed us to claim that the legacy of our PD research were two new community practices that extended over 2 years after the end of the projects and are still ongoing at the time of writing this paper. These new practices resulted from participatory activities promoted by the same participants and not directly aimed at designing new technological products. We have shown that these user-driven participatory configurations were instrumental in sustaining long-term engagement, meeting important values embedded in PD studies, especially mutual-learning and empowerment, and attaining the projects design objectives in a broader and long-term sense.

\section{Acknowledgement}

We are indebted to all the participants who took part in our study for having allowed us to become members and feel part of their communities. This research has been partially funded by the Spanish Ministry of Economy and Competitiveness (RESET TIN2014-53199-C3- 3-R ), the EU ( CIP ICT PSP-2009-4-270965 ), and Fundación General CSIC and Obra Social “la Caixa”. The authors also acknowledge the suggestions made by the reviewers.

\section{References}

Balka, E. 2010. Broadening discussion about participatory design: A reply to Kyng. Scandinavian Journal of Information Systems 22.1(2010): 77-84.

Blomberg, J., Karasti, H., 2013. Positioning ethnography within Participatory Design. Simonsen, J. and Robertson, T. (eds). International Handbook of Participatory Design. Oxford: Routledge, 86-116.

Braun, V., Clarke, V. 2006. Using thematic analysis in psychology. Qualitative research in psychology, 3(2), 77-101. 
Bjögvinsson, E., Ehn, P., Hillgren, P.A. 2012. Design things and design thinking: Contemporary participatory design challenges. Design Issues, 28(3): 101-116.

Bødker, S., Dindler, C., Iversen, O.S. 2017. Tying Knots: Participatory Infrastructuring at Work. Computer Supported Cooperative Work, 26(1-2): 245-273.

Bossen, C., Dindler, C., Iversen, O.S. 2010. User gains and PD aims: assessment from a participatory design project. Proceedings of the 11th Biennial Participatory Design Conference (pp.141-150). ACM.

Bossen, C., Dindler, C., Iversen, O. S. 2016. Evaluation in participatory design: a literature survey. Proceedings of the 14th Participatory Design Conference (pp.151-160). ACM.

Botero, A. Hyysalo, S. 2013. Ageing together : Steps towards evolutionary co-design in everyday practices. CoDesign: International Journal of CoCreation in Design and the Arts 9(1):3741.

Bratteteig, T., Wagner, I. 2016. What is a participatory design result?. Proceedings of the 14th Participatory Design Conference. Volume 1 (pp.141-150). ACM.

Chen, P.C., Wang, X. 2012. Design for well-being in China: lessons learned from exploratory workshops. Proceedings of the 12th Participatory Design Conference: Exploratory Papers, Workshop Descriptions, Industry Cases-Volume 2 (pp.81-84). ACM.

Cozza, M., Tonolli, L., D'Andrea, V. 2016. Subversive participatory design: reflections on a case study. Proceedings of the 14th Participatory Design Conference: Short Papers, Interactive Exhibitions, Workshops-Volume 2 (pp.53-56). ACM.

DiSalvo, C., Clement, A., and Pipek, V. 2013. Participatory design for, with, and by communities. In Simonsen, J. and Robertson, T. (eds). International Handbook of Participatory Design. Oxford: Routledge, 182-209.

Dittrich, Y., Eriksén, S., Hansson, C., 2002. PD in the Wild; Evolving practices of Design in Use. Proceedings of the $7^{\text {th }}$ biennal Participatory Design Conference, p.124-134. CPSR.

Fetterman, D.M. Ethnography: Step-By-Step. SAGE, Los Angeles, 2010.

Halskov, K., Hansen, N.B. 2015. The Diversity of Participatory Design Research Practice at PDC 2002-2012. International Journal of Human-Computer Studies, vol 74: 81-92.

Joshi, S.G., Bratteteig, T. 2016. Designing for Prolonged Mastery. On involving old people in Participatory Design. Scandinavian Journal of Information Systems, 28(1):3-36.

Korsgaard, H., Klokmose, C.N., \& Bødker, S. 2016. Computational alternatives in participatory design: putting the t back in socio-technical research. Proceedings of the 14th Participatory Design Conference. Volume 1, (pp.71-79). ACM. 
Leong, T.W., Robertson, T. 2016. Voicing values: laying foundations for ageing people to participate in design. Proceedings of the 14th Participatory Design Conference: Full papers-Volume 1 (pp.31-40). ACM.

Lindsay, S., Jackson, D., Schofield, G., Olivier, P. 2012. Engaging older people using participatory design. Proceedings of the SIGCHI Conference on Human Factors in Computing Systems,1199-1208. ACM.

Millen, D.R. 2000. Rapid ethnography: time deepening strategies for HCI field research. Proceedings of the 3rd conference on Designing interactive systems: processes, practices, methods, and techniques (pp.280-286). ACM.

Mitchell, R. and Nørgaard, M. 2011. Using DIY cartoon storyboards, live sketching and cosketching to involve young and older users in participatory design. Design Research IASDR,(2011), 1-8.

Newell, A.F. 2011. Design and the Digital Divide. Insights from 40 years in Computer Support for Older and Disabled People. Morgan \& Claypool Publishers.

Otjacques, B., Krier, M., and Feltz, F. 2010. Designing for Older People: A Case Study in a Retirement Home. USAB, 177-194.

Pipek, V., Wulf, V. 2009. Infrastructuring: Toward an integrated perspective on the design and use of information technology. Journal of the Association for Information Systems, 10(5): 1.

Rice, M. and Carmichael, A. 2011. Factors facilitating or impeding older adults' creative contributions in the collaborative design of a novel DTV-based application. Universal Access in the Information Society 12(1): 5-19.

Robertson, T., Leong, T.W., Durick, J., Koreshoff, T. 2014. Mutual learning as a resource for research design. Proceedings of the 13th Participatory Design Conference: Short Papers, Industry Cases, Workshop Descriptions, Doctoral Consortium papers, and Keynote abstracts-Volume 2 (pp.25-28). ACM.

Rogers, Y., et al. 2014. Never too old: engaging retired people inventing the future with MaKey MaKey. Proceedings of the SIGCHI Conference on Human Factors in Computing Systems, 3913-3922. ACM.

Sayago, S., 2009. Human-Computer Interaction with Older People: From Factors to Social Actors. Universitat Pompeu Fabra, Ph.D. dissertation.

Sayago, S., Rosales, A., Righi, V., Ferreira, S.M., Coleman, G.W., \& Blat, J. 2016. On the conceptualization, design, and evaluation of appealing, meaningful, and playable digital games for older people. Games and Culture, 11(1-2):53-80. 
Silverstone, R., Haddon. L., 1996. Design and the Domestication of ICTs : Technical Change and Everyday Life. In Communication by Design. The Politics of Information and Communication Technologies, Roger Silverstone and Mansell R.(Eds.).

Storni, C. 2010. Multiple forms of appropriation in self-monitoring technology: reflections on the role of evaluation in future self-care. Intl. Journal of Human-Computer Interaction, 26(5):537-561.

Taylor, N., Cheverst, K., Wright, P., \& Olivier, P. 2013. Leaving the wild: lessons from community technology handovers. Proceedings of the SIGCHI Conference on Human Factors in Computing Systems, 1549-1558. ACM.

Uzor, S., Baillie, L., Skelton, D. 2012. Senior designers: empowering seniors to design enjoyable falls rehabilitation tools. Proceedings of the SIGCHI Conference on Human Factors in Computing Systems, 1179-1188. ACM.

Vines, J, et al. 2012. Questionable concepts: critique as resource for designing with eighty somethings. Proceedings of the SIGCHI Conference on Human Factors in Computing Systems, 1169-1178. ACM. 